\title{
Technological challenges to assess $n-3$ polyunsaturated fatty acids from marine oils for nutritional and pharmacological use
}

\author{
By A. Valenzuela*(1), S. Nieto (1) and R. Uauy (2) \\ (1) Unidad de Bioquímica Farmacológica y Lípidos y \\ (2) Unidad de Nutrición Clínica. INTA. \\ Universidad de Chile. \\ Casilla 138-11, Santiago, CHILE.
}

RESUMEN

Retos tecnológicos para evaluar ácidos grasos $\mathrm{n}-3$ poliinsaturados de aceites marinos para uso nutricional y farmacológico.

Los beneficios atribuidos a los aceites marinos ricos en ácidos grasos $\mathrm{n}-3$ poliinsaturados han conducido a un esfuerzo por mejorar las características químicas y organolépticas de estos aceites y al desarrollo de procedimientos para la obtención de fracciones altamente concentradas o puras de ácidos grasos $n-3$. Dos ácidos grasos $n-3$ de interés principal son el ácido eicosapentaenoico (C20:5, EPA) y el ácido docosahexaenoico (C22:6, DHA). La presente revisión está referida a la identificación de las principales fuentes de ácidos grasos n-3 poliinsaturados marinos, y a la estabilización de estos ácidos frente a la rancidez oxidativa. Además de los procedimientos para la obtención de concentrados de EPA y DHA, es también discutida la utilización de estos ácidos grasos para usos nutricionales y farmacológicos.

PALABRAS-CLAVE: Aceite marino - Acido graso poliinsaturado Información (artículo) - Propiedad farmacológica - Propiedad nutricional.

\section{SUMMARY}

Technological challenges to assess $n-3$ polyunsaturated fatty acids from marine oils for nutritional and pharmacological use.

The benefits ascribed to marine oils rich in $n-3$ polyunsaturated fatty acids has led to efforts to improve the chemical and organoleptic characteristics of these oils and to develop procedures for the obtention of pure or highly concentrated fractions of some n-3 fatty acids. Two n-3 fatty acids are of main interest; the eicosapentaenoic acid (C20:5, EPA) and the docosahexaenoic acid (C22:6, DHA). The present review is referred to the identification of the main sources of marine n-3 polyunsaturated fatty acids, and to the stabilization of these fatty acids against oxidative rancidity. In addition the procedures for the obtention of EPA and DHA concentrates and the utilization of these fatty acids for nutritional or pharmacological purposes are also discussed.

KEY-WORDS: Information (paper) - Marine oil - Nutritional property Pharmacological property - Polyunsaturated fatty acid.

\section{INTRODUCTION.}

The increasing interest in the nutritional and pharmacological properties described for the $n-3$ polyunsaturated fatty acids contained in marine oils (Simopoulus, 1991), has led to efforts to improve the chemical and organoleptic characteristics of these oils and to develop procedures for the obtention of pure or highly concentrated fractions of some $n-3$ fatty acids. The beneficial effects for human health ascribed to marine oils are mainly related to its relative high content of eicosapentaenoic acid (EPA, 20:5 n-3) and docosahexaenoic acid (DHA, 22:6 n-3) (Bang \& Dyerberg, 1986), which have concentrations totaling $24-33 \%$ of the fatty acid content of the oil depending on the type of fish and season of capture (Ackman, 1964). In this context, any method applied to improve the chemical and organoleptic characteristics of marine oil must keep the EPA and DHA composition unaltered and must provide higher concentrations of these fatty acids. The present review deals with the identification of the principal sources for $n-3$ polyunsaturated fatty acids, with the efforts currently made to stabilize these fatty acids against oxidation, with the different procedures for the obtention of EPA and DHA concentrates at laboratory and industrial scale, and with the possible utilization of these fatty acids aiming the application of their nutritional and pharmacological benefits.

\section{MARINE OILS AS A SOURCE OF N-3 FATTY ACIDS IN OUR DIET.}

Plants are good sources of PUFA. Most oil seeds contain predominantly linoleic acid (C18:2, n-6) and some alpha linolenic acid (C18:3, n-3). This latter fatty acid has higher concentrations in chloroplast membranes of leafy vegetables rather than in oil seeds. N-3 fatty acids of marine origen are formed in the chloroplast of marine plants that form part of the phytoplankton or algae consumed by fish. The main source for the novo synthesis of n-3 fatty acids are marine autotrophic bacteria, algae and protozoa which constitute the phytoplankton and the zooplankton (Seto et al. 1984, Iwamoto et al. 1986). Fish, higher in the marine food chain incorporate the n-3 PUFA and further elongate them to 20 and 22 carbon atoms fatty acids containing four, five and up to six double bonds by the action of specific desaturases. Thus fish will concentrate EPA and DHA as triglycerides, mainly in the adipose tissue and in the fat of muscle and visceral organs (Brockenhorff et al. 1963). Therefore the higher fat of fish, the higher its content in n-3 fatty acids. Some marine mammals, such as seals and polar bears which feed predominantly fish, also accumulate relatively high quantities of $n-3$ fatty acids in their adipose tissue (Ackman, 1964).

Marine bacterial strains isolated from the intestinal content of some fish show a remarkably high content of EPA 
and DHA (Akimoto et al. 1988), therefore efforts have been made to grown these microorganism in natural or artificial sea water aiming the obtention of EPA and DHA for nutritional or pharmacological use. The experimental production of some strains of these bacterias has been succesful, however massive production commercially advantageous is far to be profitable relative to the cost of concentrates obtained from marine oils. Several filamentous fungi belonging to the genus Mortierella have been found to produce large amounts of EPA in their mycelia when are grown at low temperature (Shimizu et al. 1988). These fungal may be promising as a practical source for omega-3 fatty acids obtention providing their masive production may be commercially profitable.

Presently the processing of pelagic fish (those feeding and living at the surface) is the main industrial source of $n$ 3 fatty acids. These fatty acids are present in relative high concentrations (14\% to $30 \%$ EPA + DHA) in fish oil, a second product of fish meal manufacture. Fish oil may be also obtained from the visceras of some oily fish (as in cod liver oil). Basically, whole or scrap fish are cooked, in order to denaturate proteins, break down the tissues and release the oil. In the early stages of their preparation for food use, oils generally contain non-triglyceride substances in small amounts. Some of these may detract from acceptability for human consumption because of the flavors and odors which they impart to the oil or because they reduce its stability or shelf-life. Oils intended for edible purposes need to be refined to remove these substances while retaining their desireable features. The substances which affect acceptability include: moisture, insoluble impurities, free fatty acids, trace metals, oxidation products, sulfur, halogen and nitrogen compounds, pigments sterols, trace metals and organic contaminants from the enviroment (Bimbo, 1988). Further processing steps used include winterization to remove low melting point triglycerides for clarity at refrigerator temperatures; degumming to remove phosphatides and protein-acueous materials; neutralization to remove free fatty acids and some pigments; bleaching to remove pigments, oxidation products, trace metals, and soaps; and deodorization or steam tripping to remove volatiles components including some pigments and chlorinated pesticides. Figure 1 show a balance material for fish meal and fish oil separation and figure 2 show the main stages for fish oil processing.

Procedures for deodorization merits special attention because it is of especfic concern for the final EPA and DHA content of the oil. In the cases where the ultimate end use of the oil is margarine or shortening manufacture, a hydrogenation step is performed prior the deodorization step. However, a considerable reduction in the EPA and DHA content of the oil is produced when this procedure is applied. For this reason conventional procedures for deodorization (i.e steam tripping at $200-240^{\circ} \mathrm{C}$ ) are not suitable (Chang, 1988). Different strategies to prevent this have been sought. We have developed a pilot-scale procedure for deodorizing fish oil by high vacuum distilation at low temperature (below $150^{\circ} \mathrm{C}$ ) (Dinamarca et al. 1990). This procedure keeps the EPA and DHA content of the oil and

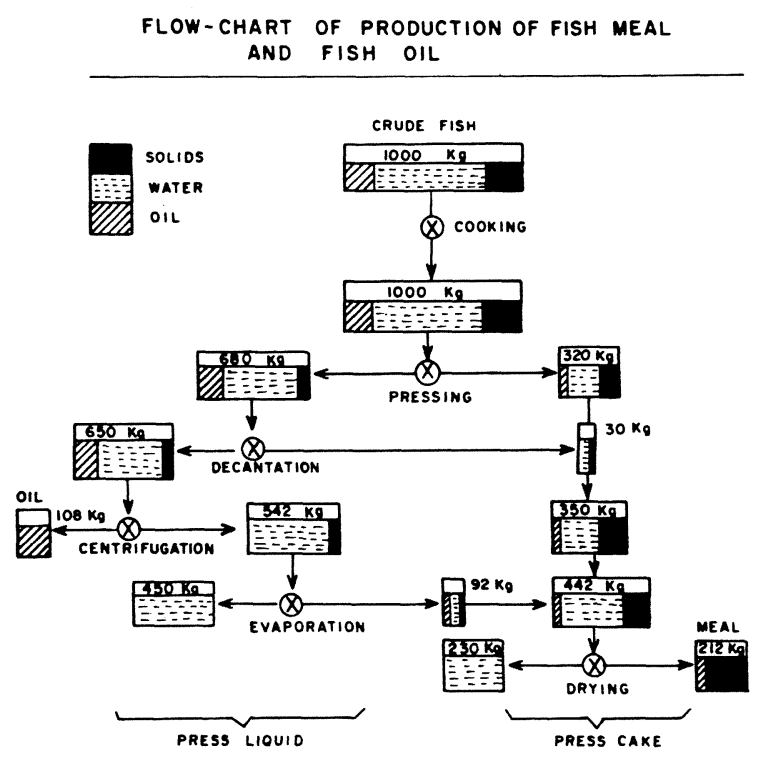

Fig. 1.

Flow-Chart of production of fish meal and fish oil

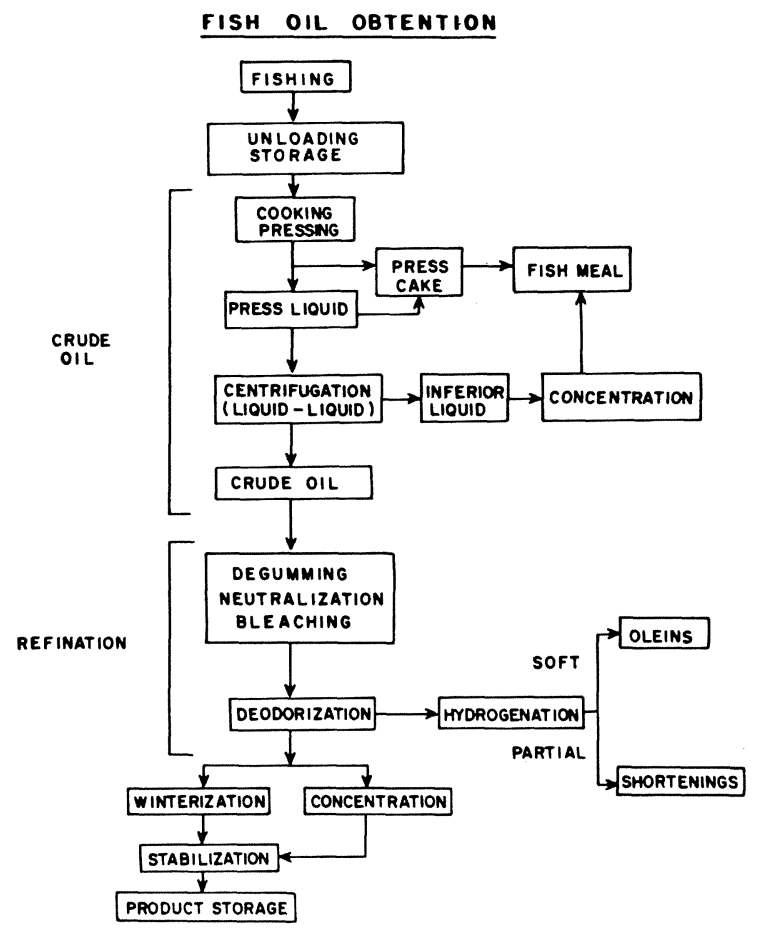

Fig. 2.

Fish oil obtention

reduces considerably the peroxide value and the cholesterol content of the product.

Marine oil obtained from sardine, menhaden or anchovy, is the main source of n-3 PUFA at the present time. In addition to the health uses as supplement fish oil is utillzed in a number of industrial applications such as in the manufacture of soaps, paints and varnishes, rubber lubricants, 
leathers and cosmetics. The world production of fish oil is estimated in 1, 500 TM/year Japan, United States, Norway, Chile and Peru are the largest producers on global basis (Barlow, 1988).

\section{OMEGA-3 FATTY ACID CONTENT OF MARINE FOODS, VARIABILITY AND SOURCES OF VARIA- BILITY.}

The public and even clinical investigators studying the potencial therapeutic and nutritional effects of fish oil are not fully aware of the considerable variability of the fatty acid and lipid composition of different fish. Variability depends not only on seasonal variation in feeding habits of marine animals, but also on the foods available to fish, and on regional differences in the composition of basic foods and nutrient (Farkas et al. 1980). The variability of the n-3 PUFA content of marine foods depends on the specie of fish, the place and the season of capture and on the industrial processing of the fish. The lipid content in edible parts of seafood may range from $0.5 \%$ to as much $25 \%$. From this standpoint marine animals can be classified in four groups depending on their lipid content (Ackman, 1990): 1- Lean (<2\% fat); cod, haddock, shellfish. 2- Low fat ( $2-4 \%$ fat); sole, halibut, flounder. 3Medium fat (4-8\% fat); salmon. 4 - High fat ( $>8 \%$ fat); menhaden, herring, sardine, anchovy. Table I show the n-3 content of different fish oils. Menhaden oil and sardine oil show a higher content of EPA than DHA, while other like anchovy oil show almost an equal concentration of both fatty acids. The place and season of capture may produce broad changes in the $n-3$ content of the oil even for the same fish. As the temperature of water decreases, as in the polar regions, fish increase the degree of polyunsaturation of the fatty acids of their tissues in order compensate the reduction in the fluidity of membranes due to low temperature. On the contrary, when the capture occurs in temperate regions where the sea water temperature is over $12^{\circ} \mathrm{C}$, the oil obtained after fish processing may show a significant reduction in its $n-3$ content. By a similar mechanism the season of the capture may also influence the n-3 content of the same specie (Olsen et al. 1991). The conditions for the preservation of fish after capture and the latter processing at the industrial plant may be determinant in the final content of $n$ 3 fatty acids of the oil.
In processing fish for edible use, the first and foremost requirement is the quality of the raw material. The fish should be undamaged and chilled from the time of catch to prevent deterioration (Young, 1990). A considerable reduction in the loss of $n-3$ fatty acids of the oil is obtained by maintaining fish at low temperature as it is stored in the ship and in the factory before processing. However, since fishing is primarily directed to the manufacture of fish meal, no especial precautions are taken to preserve fish in a way that protects the quality of the oil. Fish meal manufacture requires the application of high temperatures and different mechanical procedures (cooking, pressing, centrifugation, filtration, etc) all of which adversely affect the quality and final composition of the oil.

\section{TECHNOLOGICAL APPROACHES TO EXTRACT AND PRESERVE OMEGA-3 FATTY ACIDS FROM MARINE OILS.}

In order to maintain the original structure of the PUFA, great care must be taken in handling and storing oils. PUFAs, especially those with methylene interrupted diene system, such as EPA and DHA, are extremely susceptible to oxidation. They react readely with atmospheric oxygen and produce undesirable products which affect flavors. Heavily oxidized oils are no longer suitable for nutritive purposes, because the oxidation products of the unsaturated fatty acids have toxic effects (Cadenas, 1989). Preservation of fish oil against deterioration is an ancient challenge not yet fully resolved. Fish oil as most PUFAs is highly susceptible to undergo oxidative rancidity, a physicochemical process that destroys the carbon structure of the fatty acids forming a number of oxidative products (as aldehydes, peroxides, hydroperoxides, alcohols, etc), many of them of potential toxicity either for humans and for animals (Khayat \& Schwall, 1983). This structural transformation is initiated by oxygen or more presicely, by active forms of oxygen, "oxygen free-radicals". Many chemical reactions which occur normally in our bodies produce oxygen free-radicals as unavoidable products (Aikens \& Dix, 1991, Frankel, 1984). Free radicals, such as the superoxide free-radical (02-), the hydroxyl free-radical (HO.) and the peroxyde free radical (ROO.), are highly reactive and may attack the structure of the polyunsatu-

Table I

Unsaturated fatty Acid Composition (g/100g) of Major Commercial Fish Oils

\begin{tabular}{|c|c|c|c|c|c|c|}
\hline FISH OIL & $\begin{array}{c}16: 1 \\
n-7 \\
\end{array}$ & $\begin{array}{c}18: 1 \\
n-9\end{array}$ & $\begin{array}{c}20: 1 \\
n-9 \\
\end{array}$ & $\begin{array}{c}22: 1 \\
n-9 \\
\end{array}$ & $\begin{array}{c}20: 5 \\
n-3 \\
\end{array}$ & $\begin{array}{c}22: 6 \\
\mathrm{n}-3 \\
\end{array}$ \\
\hline Menhaden & 11 & 10 & 1 & trace & 16 & 9 \\
\hline Sardine & 7 & 13 & 8 & 6 & 16 & 10 \\
\hline Anchovy & 9 & 13 & 5 & 2 & 11 & 10 \\
\hline Herring & 6 & 13 & 13 & 20 & 5 & 6 \\
\hline Cod liver & 10 & 23 & trace & 5 & 11 & 12 \\
\hline
\end{tabular}


rated fatty acids leading to its oxidative transformation (Aikens \& Dix, 1991).

Development of oxidative rancidity may be accelerated by both chemical and physical factors (Frankel, 1984). Natural or artificial light will enhance the development of rancidity. In the same direction, the temperature of the recipient where the oil is contained may significantly reduce the time for development of rancidity. However, the presence of some metal contaminants, acquired in the processing or from the recipient where the oil it is contained, are the most important contribution to the deteriorative effect of oxidative rancidity. Metals as $\mathrm{Fe}_{2}^{+}, \mathrm{Cu}_{2}^{+}, \mathrm{Ni}^{+}$or $\mathrm{Co}_{2}^{+}$at ppm concentrations act as catalysts of oxidative rancidity by shortening the induction time for the oxidation (Aust, 1989). The vulnerability of oils to damage by oxygen free-radicals is directly related to the degree of unsaturation. It has well stablished that the more unsaturated the oil, the more susceptible to develop oxidative rancidity it is. The number of pentadienic units present in a PUFA is directly related to its rate of oxidation (Nawar, 1988). Therefore those fish oil with a high content of EPA + DHA, are the more susceptible to develop oxidative rancidity. This oxidative process, which may not be inhibited at all as will be discussed bellow, is a major restriction for the management and in the application of fish oil or fish oil containing-products for human and animal nutrition. Major efforts in the search of natural or synthetic substances that may safely protect fish oil against oxidative rancidity have been undertaken (Nawar, 1988., Namiki, 1990). Table II summarizes the main chemical and physical conditions affecting the stability of fish oils.

Ingestion of high doses of n-3 fatty acids leaves the question about the risk to develop tissue oxidative rancidity. By eating fish or fish oils we load our phospholipids with EPA and DHA at the expense of their content of arachidonic acid, increasing the susceptibility of lipid membranes to oxidative damage. This effect has been observed in experimental animals by several authors (Malis et al. 1990, Garrido et al. 1989, Leibovitz et al. 1990). Moreover, age appears as an important factor in the development of these susceptibility. Aged rats, fed fish oil show a higher susceptibility to develop tissue lipid peroxidation than young ones (Garrido et al. 1992).

\section{PRINCIPLES FOR PHYSICAL SEPARATION OF FATTY ACIDS.}

Fish oil is presently available from the food and drugstore market in a variety of ways. Crude and refined fish oil are prepared as soft-gel capsules, water emulsions or mixed with vegetable oils. Ingestion of fish oil capsules is the most popular source to obtain n-3 fatty acid supplementation. Different encapsulated products marketed commercially as MaxEPA, EPA-SAN FORTE, Promega, EPA-CHOL or OMEGA-CON containing EPA + DHA concentrations ranging from $25 \%$ to $55 \%$ (Ackman et al. 1989) are readily available and by now are relatively unexpensive. A $500 \mathrm{mg}$ capsule of these products provide 125 to $225 \mathrm{mg}$ of $\mathrm{n}-3$ fatty acids. Although a daily requirements for these fatty acids have not yet well stablished for humans and probably are different depending on the age and nutritional status of individuals, it is assumed that the ingestion of one or two capsules provide enough EPA and DHA to meet the needs for optimal health requirements (Bjerve, 1989).

However, the ingestion of fish oil in any form may be accompained by some adverse side-effect as gastritis and esophageal flatulence with fishy-odor. Moreover, crude fish oil also contains fatty acids which are considered as hazardous for health (as cetoleic acid , C22:1) (Clandinin, 1989). Thus, in considering safety and nutritional efficacy it seems advisable that the consumption of EPA and/or DHA be in pure form or as refined oils highly concentrated in these fatty acids.

Newer manufacturing techniques may provide consumers with fish oil preparations containing large amounts of EPA and DHA than presently available. Most attempts to prepare highly concentrated n-3 PUFAs involve large amounts of solvents, consecuently cost are high and yields are low. The main problem in obtaining these concentrates is the complexity of the combinations of the fatty acids in the triglycerides of the oil. The commercial production of concentrates highly enriched in EPA and/or DHA is now a mayor challenge for the food scientist working with marine oils. High concentrations of $n-3$ PUFAs are desirable for clinical therapy or where high intake of fish oil is not tolerated. Simple fractionation processes do not discriminate among the different polyunsaturated

Table II

Chemical and Physical Conditions Affecting Fish Oil Stability

\begin{tabular}{ll}
\hline DETERIORATIVE CONDITIONS & PROTECTIVE CONDITIONS \\
\hline Unrefined or partially refined & Highly refined and high vacuum distillation \\
\hline Oxygen exposure & Inertatmosphere \\
\hline Absence of natural or added antioxidants & Addition of synthetic and/or natural antioxidants \\
\hline Presence of trace metals from proccessing and/or recipient & Avoiding of metal contaminants and/or addition of metal chelating agents \\
\hline Preservation at room or higher temperatures & Preservation at low temperatures \\
\hline Exposure to natural or artificial light & Preservation in opaque and sealed recipients \\
\hline
\end{tabular}


fatty acids present in fish oil and are not useful for enriching oils in EPA or DHA.

Several methods have been developed to prepare fractions enriched in EPA and DHA. Due to high cost, however, these methods are most suitable for small-scale laboratory preparation of purified samples rather than to the processing of large amounts of fish oil. Techniques suitable for smallscale preparation of EPA and DHA concentrates include controlled winterization (Gunstone et al. 1976), urea adduct fractionation (Wright et al. 1987), and silver resin chromatography (Adlof \& Emken, 1985). Controlled winterization of the methyl or ethyl ester of the triglycerides is a low cost technique but provides low concentrations for each fatty acid (Valenzuela et al. 1992). Urea complexing is a well proven technique for eliminating saturated and monounsaturated fatty acids and becomes an atractive proposition to concentrate EPA and DHA. Large scale chromatography with silver ions bounded to cationic resins is possible but it is a very expensive procedure. Although other chromatographic techniques are available, these require large volumes of solvents that increases the cost of processing. Supercritical gaseous (carbon dioxide) extraction has been described as useful in producing highly purified unsaturated fish oil fractions (Nelson, 1982). It has attractive features in terms of milder physico-chemical conditions, but using presently available technology, has high capital costs for large scale work. Concentrations up to $96 \%$ of EPA have been achieved by first converting the triglycerides to alkyl esters followed by urea precipitation and supercritical carbon dioxide fractionation (Latta, 1990). However the equipment needed and the high cost for operation (over U\$ 2,700/kg) make the procedure prohibitively expensive given the present uses of the product. Figure 3 depicts a scheme of the available technologies for EPA and DHA concentration procedures.

PROCEDURES FOR OBTAINING EPA + DHA CONCENTRATES

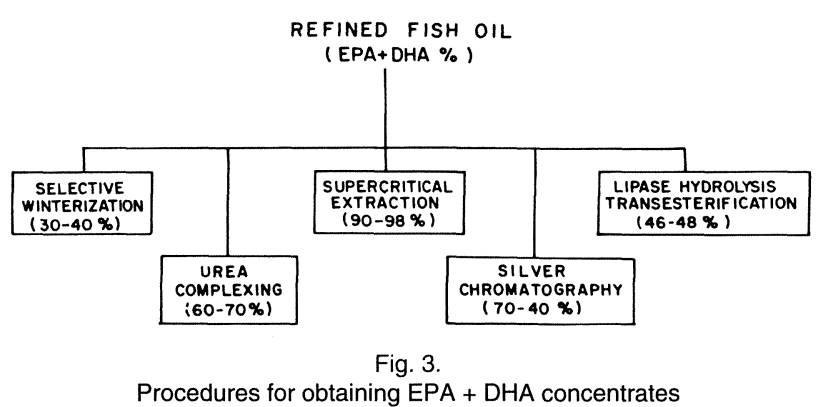

Another potential approach for the obtention of EPA and DHA enriched fractions from fish oil may be the use of product specific lipases combined with urea adduct concentration. The bacterial lipase obtained from Mucor miehei is highly specific for the sn-1' and $3^{\prime}$ position (Sonnet \& Gazzillo, 1991). Since most polyunsaturated fatty acids are located in the sn-2' position of glycerol in the triacylglycerides of fish oil (Brockenrhoff, 1965), the selective hydrolysis of these triacylglycerides by a 1-3 specific lipase yields mainly EPA and DHA monoacylglycerides. The EPA and DHA 2'-acylglycerides may be easily separated from other monoesters by silver resin chromatography (Langholz et al. 1989). In a parallel process, methylation or ethylation of fish oil triacylglycerides by the corresponding sodium oxide yields the esthers that can be separated by urea complexing at controlled temperature. This allows for the obtention of relatively concentrated EPA and DHA ethyl or methyl esters. If these products are then reacted with the corresponding EPA or DHA monoacylglycerides (obtained from the lipase action) in the presence of the same lipase but in a hydrophobic medium, the enzyme behaves as a transesterase allowing for the formation of EPA and DHA pure triacylglycerides (Osterberg et al. 1989). This procedure has been succesfully tested by us on a laboratory-scale yielding highly purified fractions of triacylglycerides enriched in one specific fatty acid (Valenzuela et al. 1992). This procedure for the synthesis of "structured lipids" or "designed lipids" has the potential for changing drastically the nutrition of lipids as we know to day. We will no longer be limited by what is available to us from nature but we may be able to test the physiologic and therapeutic effects of lipids mixtures which are specifically design to attack a given problem. Figure 4 represents a model for obtaining pure EPA and DHA triglycerides using the lipase hydrolysis and transesterification methodologies.

\section{PROCEDURE FOR OBTAINING EPA AND DHA TRIGLYCERIDES}

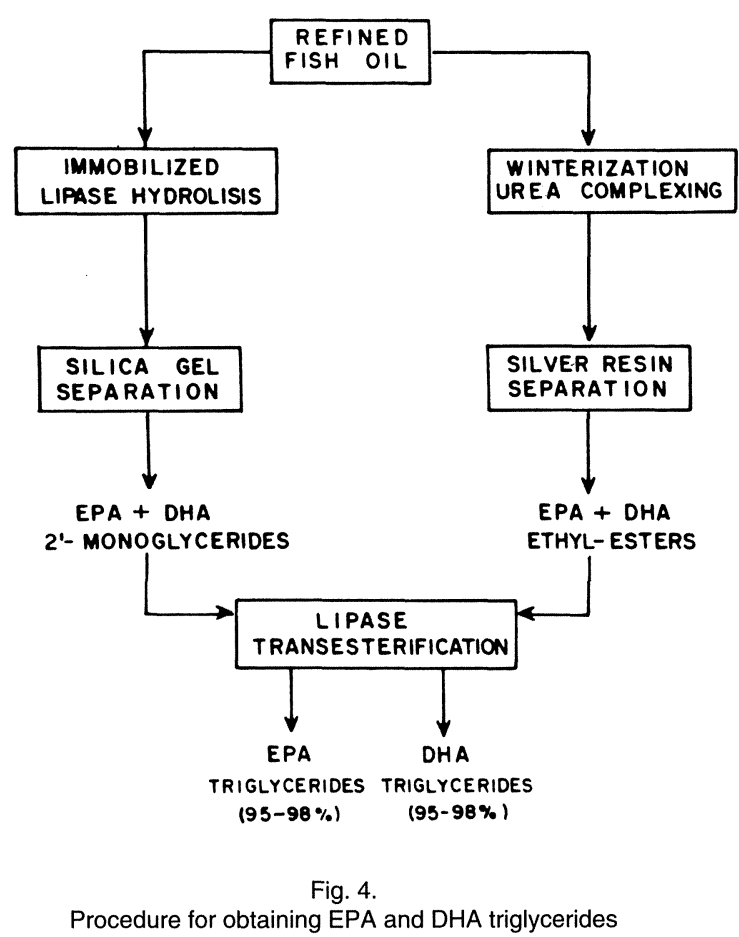

Present industrial efforts have succeeded in placing different $n-3$ fatty acid concentrates in the market, either as pure fatty acids, as methyl or ethyl esters, or as mixtures of free fatty acids (mainly EPA + DHA). The technology to obtain these concentrates is protected by industrial patents. 
Selective winterization followed by urea precipitation is the most frecuently used method. These concentrates may now be applied as such, or encapsulated in the enrichment of foods or foods supplements. The main limitation in this application is the high cost of the concentrates. A kilogram of EPA or DHA $98 \%$ have a price in the range of U\$ 15,000 (Pharmaglobe Laboratories, Ontario, Canada). The methodologies decribed in this section are now being taken to the industrial scale. The present challenge is to develop cost effective ways to producing industrial scale amounts of purified EPA and DHA compounds to meet the growing demand for this nutrients. Possible applications of marine oils and EPA/DHA concentrates are depicted in figure 5.

POSSIBLE APPLICATIONS OF MARINE OILS

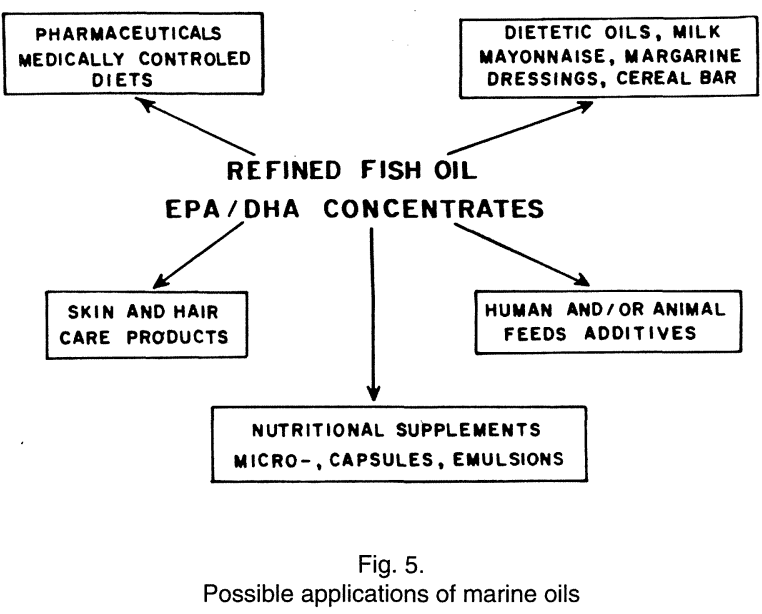

\section{HOW TO PREVENT OXIDATIVE RANCIDITY OF MARINE OIL FRACTIONS.}

Oxidative rancidity of fish oil is a major problem limiting its use for human consumption. As discussed above the high unsaturation of some fatty acids present in fish oil makes it extremely susceptible to oxidation even when precautions are taken. To minimize oxidation adecuate conditions of preservation such as refrigeration, protection from light, and storage in inert airtight containers are used (de Konig \& Milkovitch, 1989; Logani \& Davies, 1980).

Antioxidants are natural or synthetic compounds that suppress or retard the oxidation. They interfere with the initiation steps of oxidation (induction period) or with the early propagation steps (Labuza, 1971). Antioxidants may react with the free radicals formed in the initial or early steps of oxidation to give intermediate products that terminate the process. Antioxidants such as tocopherols occur naturally in fish oils in small amounts but are lost during processing.

Antioxidants to be useful should be highly effective at low concentrations, reasonably priced, and readily soluble.
Furthermore they should be approved for use in food and should not mask the effect of improper processing or storage or contribute to off-flavors (Stansby, 1971). Antioxidants are usually added directly to the oil at approximately $0.02 \%$ to $0.08 \%$. Synthetic antioxidants have been largely used in fish oil preservation, butylated hydroxy anisole (BHA), butylated hydroxy toluene (BHT), propyl gallate, and terbutylhydroxyquinone (TBHQ) are commonly used singly or mixed. These antioxidants have been included in products directed for human or animal consumption or for different industrial applications. However, the use of these antioxidants as additives in foods destined for human consumption has been questioned (Branen, 1975). These synthetic substances have been shown in animal models to cause a variety of pathologic signs: enlarged liver size, increase liver microsomal enzyme activity, modifying other ingested materials into toxic or carcinogenic substances, especially if they are present in excessive amounts (Ito et al. 1986). BHA has been removed from the GRAS (generaly recognized as safe) category, the use of $\mathrm{BHT}$ has been restricted by the regulatory agencies of some european and american countries. Presently, TBHQ is the only effective antioxidant allowed in the USA and its use is mainly limited to lipids and oils for human consumption, yet it is not authorized in some European countries (Papas, 1991). More attention should be given to the search of new natural agents that can suppress or retard oil oxidation.

Alternatives to synthetic antioxidants are commercially available now in United States and some European countries although most are generally more costly and in some mixtures are less efective. Tocopherols have been proved as effective antioxidants for fish oil (Ackman, 1991). Of the different isomers of tocopherols gamma is the most effective as antioxidant, yet alpha tocopherol is the most frecuently used due its lowest cost. Other products of vegetable origen have been assayed as antioxidants for fish oils, species as clove, cinnamon, rosemary, oregano, and allspice have demonstrated highly antioxidant properties and strong synergism when combined with some synthetic antioxidants (Chipault et al. 1956). Out of these products, rosmaridiphenol is the only spice commercially available for use as an antioxidant (Houliham et al. 1984). Drawbacks to using rosemary, however, include its high cost relative to the synthetic antioxidants and the larger quantities that often must be used to obtain the same effect.

Research in our laboratory is now directed to the study of natural substances with antioxidant activity. Several plant products have been tested by us as antioxidant for use in fish oil. Some commercial flavonoids as quercetin and morin or new flavonoids extracted from the autoctonous flora from the north region of Chile show powerfull antioxidants properties when assayed on fish oil added either as single species or in mixtures with other antioxidants (Nieto et al. 1992). We have recently reported that boldine, the most abundant alkaloid present in the leaves and bark of boldo (Peumus boldus Mol), a widely distributed native tree of Chile, show a good stabilizing action against fish oil oxidation, either spontaneous or metal-induced. (Valenzuela et al. 1991). We are presently undertaking rigorous toxicological 
testing to assess the potential future use of this newly identified natural antioxidants. However, we are encouraged by the fact that native populations of the region have drank herbal infusion of the leafs of this tree by generations.

\section{HOW TO INCORPORATE OMEGA-3 FATTY ACIDS IN OUR DIET.}

In general meats and animal products of terrestrial animals are poor sources of $\mathrm{C} 20$ and $\mathrm{C} 22$ n-3 fatty acids. These animals tend to emphasize the synthesis of those fatty acids of $n-6$ structure in the longer chain lengths. Although fish products are the major source of C20 and C22 fatty acids in the western diet, it has been proposed that this dietary intake from fish may be supplemented by the contribution by one of the most widely accepted and eaten terrestrial meats, that of the common broiler chicken Ackman et al. (1988), have demonstrated that the chicken has a natural predisposition to accumulate EPA and DHA formed from the precursor C18:3 n-3. They also have demonstrated that this effect could be amplified by the inclusion of fish meal in the feed without affecting flavor. Feeding chickens with fish meal as a major constituent of the diet is now feasible due the high quality products which can be obtained from the market. The lipids in fish meal may account for some of the alledged health beneficts attributed to chicken meat consumption. The lipids in white fish meal ("prime" quality) made primary from lean fish muscle trimmings contain a high proportion of readily digested fish phospholipids (Ackman, 1980)

In addition to the natural sources of EPA and DHA provided by fish or chicken meat consumption, EPA and DHA concentrates may be applied as supplements in the manufacture of as number of dairy products as mayonnaise, milk or milk-derived products, margarines and table spreads, vegetable edible oils or mixtures of partially hydrogenated fish oil and vegetable oil, emulsified or nonemulsified shortenings, hard fats, pastry fats, biscuits and bread doughs, etc. (Orthoefer, 1989). However these and future other application for EPA and DHA concentrates will be commercially feasible provided low cost are obtained. In addition, these should be highly stable against oxidation, and easy to incorporate to industrially manufactured products. The answer to these and other limitations for the practical use of $n$ 3 concentrates is a great challenge for the food scientists and technologists during the present decade.

While the major portion of the food use of marine oils is in the partially hydrogenated form, there is growing interest in looking at food systems where the omega-3 fatty acids remain unchanged or the content of these fatty acids may be increased from the bottled oil, oil-water emulsions and soft-gel capsules that are expended in the market and profusely advertised. There is now an increased amount of work in progress looking the developing of foods incorporating omega-3 fatty acids.

A technological approach to incorporate fish oil concentrates or pure forms of EPA and DHA in ordinary or novel foods is microencapsulation. This technique has important potential applications for use in animal feeding and in direct human consumption since it facilitates the incorporation of $n-3$ fatty acids. Microencapsulation of fish oil concentrates could improve the stability of products, may serve to overcome palatability problems reducing unpleasant taste or odor or gastric irritation (Bimbo,1987). However caution must be excercised prior to promoting the use of microencapsulated fish oil or n-3 concentrates. The major corncerns are centered on the question of stability, acceptability, and assimilation of the product. Further studies need to be performed to determine the shelf life of microencapsulated oil concentrates. The composition of the capsule shel material is also of concern since it should not induce toxic manifestations, nor react with the material to which is mixed, or cause it to degrade (de Konig \& Milkovitch, 1989). The main function of capsules of oils highly concentrated in EPA and/or DHA will most likely in clinical therapy, but dietary supplementation with other fish oil products can not be ruled out since they are freely available to consumers. Current evidence suggest that most adults most successfully obtain good health beneficts with 1-2 g EPA per day (Simopoulus, 1991), this quantity being provided by $14-18 \mathrm{ml}$ of fish oil. Since few people wish to consume these volume daily, it appears that concentrates of either EPA or EPA + DHA will definitely form the bulk at the market.

\section{ACKNOWLEDGEMENTS}

The work of the authors was supported by FONDECYT (grants 1071-91 and 1930808), UN Development Program (grant $\mathrm{CHI} / 017 / 88$ ), and by Corfo-Corpesca (Chilean Fish Meal Producers Association).

\section{REFERENCES}

Ackman, R. G. (1964).- "Structural homogeneity in unsaturated fatty acids of marine lipids" - J. Fish Res. Board Canada 21, 247-254.

Ackman, R. G. (1980).- "Fish Lipids".- In: Advances in fish sciences and technology. Connell, J.J. ed. Fishing new books, U. K. pp 86-103

Ackman, R. G. (1990).- "Variability of fatty acids and lipids in seafoods".Omega-3 news $\mathrm{V}, 1-4$

Ackman, R. G. (1991).- "Oxidation susceptibility of encapsulated fish oil products: a comparison of triglycerides versus free acids".- Omega-3 news VI, 1-4.

Ackman, R. G., Lamothe, M. F., Hulan, H.W., and Proudfoot, F. (1988).- "The broiler chicken. Its current and potential role as a source of long chain $\mathrm{n}-3$ fatty acids in our diets".- N-3 news III, 1-4.

Ackman, R. G., Ratnayake, N. M., and Macpherson, E. J. (1989).- "EPA and DHA contents of encapsulated fish oil products".- J. Am. Oil Chemists' Soc. 66, 1162-1164.

Adlof, R. O, and Emken, E. A. (1985) - "The isolation of omega-3 polyunsaturated fatty acids and methyl esters of fish oils by silver resin chromatography".- J. Am. Oil Chemists' Soc. 62, 1592-1595.

Aikens, J., and Dix, T. (1991).- "Perhydroxyl radical (HOO.) initiated lipid peroxidation".- J. Biol. Chem. 266, 15091-15098.

Akimoto, M., Ishii, T., Yamagaki, K., Ohtaguchi, K., Koide, K., and Yasawa K. (1990).- "Production of eicosapentaenoic acid by a bacterium isolated from mackerel intestines". - J. Am. Oil Chemists' Soc. 67, 911-915.

Aust, S. D. (1989).- "Metal ions, oxygen radicals and tissue damage".- In Nutritional impact of food processing. Somogyi, J. C. and Muller, H. R. eds. Bibl. Nutr. Dieta 43, 266-277.

Bang, H. O., and Dyerberg, J. (1986).- "Lipid metabolism and ischemic heart disease in Greenland Eskimos" - Adv. Nutr. Res. 3, 1-21. 
Barlow, S. M. (1988).- "The challenges to the world fish oil industry".- N-3 news II, 1-3.

Bimbo, A. P. (1987).- "The emerging marine oil industry".- J. Am. Oil Chemists' Soc. 64, 706-715.

Bimbo, A. P. (1986).- "Use of fish oils: task for new technology". N-3 news I, $1-4$.

Bjerve, K. S. (1989).- "N-3 fatty acids deficiency in man: pathogenic mechanism and dietary requirements".- N-3 news IV, 1-4.

Branen, A. L. (1975).- "Toxicology and biochemistry of butylated hydroxyanisole and butylated hydroxytoluene".- J. Am. Oil Chemists' Soc. 52, 5963.

Brockenhorff, H. (1965).- "A stereospecific analysis of triglycerides".- J. Lipid. Res. 6, 10-15.

Brockenhorff, H., Ackman, R. G., and Hoyle, R. J. (1963).- "Specific distribution of fatty acids in marine lipids".- Arch. Biochem. Biophys. 100, 93100.

Cadenas, E. (1989).-"Biochemistry of oxygen toxicity".- Ann. Rev. Biochem. $58,79-110$

Chang, S.S. (1988).- "Challenges of deodorization of fish oil".- N-3 news III, 1-6.

Chipault, J. R., Mizuno, G. R., Hawkins, J. M., and Lundberg, W. 0. (1956)"The antioxidant properties of spices in foods".- Food Tech. 10, 209-211.

Clandinin, M. T., Chappel, J. E., and van Aerde, J. E. (1989).- "Requirements of newborn infants for long chain polyunsaturated fatty acids".- Acta Pediatr. Scand. 70, suppl 351, 63-71.

de Konig, A. J., and Milkovitch, S. (1989).- "The storage behaviour of a number of fish oil helth capsules at ambient temperature".- South African $\mathrm{J}$. Food Sci. Nutr. April, 7-8.

Dinamarca, E., Garrido, F., and Valenzuela, A. (1990).- "A simple high vacuum distillation equipment for deodorizing fish oil for human consumption".- Lipids $25,170-171$.

Farkas, T., Csengeri, I., Majoros, F., and Olah, J. (1980).- "Metaboilsm of fatty acids in fish. III Combined effect of enviromental temperature and diet on formation and deposition of fatty acids in the carp".- Aquaculture $\mathbf{2 0}$, 29-40.

Frankel, E. N. (1984).- "Lipid oxidation: mechanisms, products and biological significance".- J. Am. Oil Chemists' Soc. 61, 1908-1917.

Garrido, A., Garrido, F., Guerra, R., and Valenzuela, A. (1989).- "Ingestion of high doses of fish oil increases the susceptibility of cellular membranes to the induction of oxidative stress". Lipids 24, 833-835

Garrido, A., Garate, M., Campos, R., Villa, A., Nieto, S., and Valenzuela, A. (1992).- "Increased susceptibility of cellular membranes to the induction of oxidative stress is observed after ingestion of high doses of fish oil: effect of aging and protective action of dl- $\alpha$ tocopherol supplementation".Nutr. Biochem. In press.

Gunstone, F., Mc Laughlan, J., Scrimgeour, C, and Watson, A. (1976)."Improved procedures for isolation of pure oleic acid, linoleic and linolenic acids or their methyl esters from natural sources".- J. Sci. Fd. Agric. 27, 675-680.

Houilham, C. M., Ho, C-T., and Chang, S. S. (1984).- "Elucidation of chemical structure of a novel antioxidant, rosmaridiphenol isolated from rosmary".- J. Am. Oil Chemists' Soc. 61, 1036-1039.

Ito, N., Hirose, M., Fukushima, S., Tsuda, H., Shirai, T., and Tatematsu, M. (1986).- "Studies on antioxidants: their carcinogenic ans modifying effects on chemical carcinigenesis".- Food Chem. Toxicol. 24, 10711075.

Iwamoto, H., and Sato, G. (1986)- "Production of EPA by freshwater unicellular algae".- J. Am. Oil Chemists' Soc. 63, 434-438.

Khayat, A., and Schall, D. (1983).- "Lipid oxidation in sea foods".- Food Technol. 37, 130-140.

Langholz, P., Andersen, P., Forskov, T., and Schmidtsdorff, W. (1989)."Application of a specificity of Mucor miehei lipase to concentrate docosahexaenoic acid (DHA)".- J. Am. Oil Chemists' Soc. 66, 11201123.

Logani, M. K., and Davies, R. E. (1980).- "Lipid oxidation: biological effects and antioxidants, a review".- Lipids 15, 485-495.

Labuza, P. T. (1971).- "Kinetics of lipid oxidation in foods".- CRC. Crit. Rev. Food Technol. 2, 355-405.

Leibovitz, B. E., Hu, M., and Tappel, A. L. (1990).- "Lipid peroxidation in rat tissue slices; effect of dietary vitamin E, corn oil-lard and menhaden oil".Lipids 25, 125-129.

Malis, C. C., Weber, P. C. Leaf, A., and Bonventre, J. V. (1990)-"Incorporation of marine lipids into mitochondrial membranes increases susceptibility to damage by calcium and reactive oxygen species: Evidence for enhanced activation of phospholipase A2 in mitochondria enriched with n-3 fatty acids".- Proc. Natl. Acad. Sci. 87, 8845-8849.

Nawar, W. W., and Hultin, H. 0. (1988).- "Stability of fish oils".- Omega-3 news III, 1-4.

Namiki, M. (1990).- "Antioxidants/antimutagens in food".- Food Sci. Nutr. 29, 273-300.

Nelson, R. W. (1982).- "Liquid $\mathrm{CO}_{2}$ extraction and fisheries research".Mar. Fish Rev. 46, 28-33.

Nieto, S., Garrido, A., Sanhueza, J., Loyola, L., Morales, G., Leighton, F., and Valenzuela, A. (1992).- "Flavonoids as stabilizers of fish oil: an alternative to the use of synthetic antioxidants".- J. Am. Oil Chemists' Soc. Submitted.

Osterberg, E., Blomstron, A. C., and Holmberg, K. (1989).- "Lipase catalyzed transesterification of unsaturated lipids in a microemulsion".- J. Am. Oil Chemists' Soc. 66, 1330-1333.

Orthoefer, F. (1989).- "Fish oils: past ans present food uses".- J. Am. Oil Chemists' Soc. 66, 1717-1726

Olsen, Y., and Skjervold, H. (1991).- "Impact of latitude on n-3 fatty acids in wild atlantic salmon".- Omega-3 news VI, 1-4.

Papas, A. M. (1991).- "Antioxidants. Which one are the best for your pet food products".- Petfood Ind. May/june, 8-16.

Simopoulus, A. P., Kifer, R. R., Martin, R. E., and Barlow, S. M. (1991)."Health effects of $w-3$ polyunsaturated fatty acids in sea foods".- Wordl Rev. Nutr. Diet. 8, 592-661.

Stansby, M. E. (1971).- "Flavors and odors of fish oils".- J. Am. Oil Chemists' Soc. 48, 820-823.

Sonnet, P. E., and Gazzillo, J. A. (1991).- "Evaluation of lipase selectivity for hydrolysis".- J. Am. Oil Chemists' Soc. 68, 11-15.

Shimizu, S., Shinmen, Y., Kawashima, H., Akimoto, K., and Yamada, H. (1988).- "Fungal mycelia as a novel source of eicosapentaenoic acid".Biochem Biophys Res. Commun. 150, 335-341.

Seto, A., Wang, L., and Hesselitime, C. W. (1984).- "Culture conditions affect eicosapentaenoic acid conteny of chlorella minutissima".- J. Am. Oil Chemists' Soc. 61, 892-894.

Valenzuela, A., Nieto, S., Cassels, B., and Speisky, H. (1991).- "Inhibitory effect of boldine on fish oil oxidation".- J. Am. Oil Chemists' Soc. 68, 935937.

Valenzuela, A., Nieto, S., and Speisky, H. (1992).- "Obtention of EPA and DHA concentrates by lipase specific transesterification".- Lipids. Submitted.

Wright, S. W., Kuo, E. Y., and Corey, E. J. (1987).- "An effective process for the isolation of docosahexaenoic acid in quantity from cod liver oil".- J. Org. Chem. 52, 4399-4401.

Young, F. V. (1990).- "The production and uses of fish oils"-, in: Nutritional evaluation of long chain fatty acids. Barlow, S. M., and Stansby, M. E. Eds.- Academic Press, London. pp 1-23.

(Recibido: Septiembre 1992) 